\title{
Coordination Structures and Mechanisms for Emergency Decision-making in China
}

\author{
Lei Zhang \\ Sichuan Academy of Social Sciences \\ Chengdu, China 610072
}

\begin{abstract}
From a structural-instrumental perspective, the article analyses organizational structures and coordination mechanisms for China's governmental emergency decisionmaking system. The features of this system can be described as "unified leadership, classified decision, hierarchical control structure and comprehensive coordination". This bureaucratic decision-making system has highlighted the political advantages in the past years, but it also has "fragmented problems": overtopped decision-making center, separated departments, response lag, pulverization of accountability and weak coordination arrangement.
\end{abstract}

Keywords-emergency decision-making; organizational structures; coordination mechanism; emergent events; China

\section{INTRODUCTION}

Emergency refers to the larger scale events or disasters occurred in a certain area, which has a wide and negative impact and threat on society production, life and property ( $\mathrm{Ji}$ Lei et al. 2006; Xue Lan et al. 2005). Emergency decisionmaking means the process of activities that how to judge situation and then take pertinent measures when emergency arises. It aims to shorten decision lag and improve the quality of decision, eventually trying to decrease the resource loss caused by unexpected occurrences (Xue Lan et al. 2005; Zhong Kaibin 2014). Theoretical researchers, policy-makers, regulators and practitioners struggle to establish adequate structures to facilitate coordinated responses (Christensen et al. 2015; Zhang Haibo et al. 2015). A main question is: How best to organize for effective decision-making?

Public administration scholars have devoted much attention to organization, complexity, collaboration and coordination (Christensen et al. 2015). Crisis studies mainly focus on managerial or strategic security perspectives. Unconventional decision-making theories analyze the complexity and vulnerability in order to optimize the system (Zhan Chengyu 2009). However, the research on organizational structures and coordination mechanisms is less common.

We apply a structural-instrumental to examine the coordination process and mechanisms. The structuralinstrumental point of view emphasizes how the formalnormative structure of public administration influences

This work is partially supported by the General Program of Nationa Social Science Foundation of China (No.15BSH080), Annual Research Program of Sichuan Academy of Social Sciences (No.2015QN03).

Corresponding author: Zhang Lei decision-making processes by channeling attention and shaping frames of reference (March and Simon 1993; Scott 2003; Egeberg 2012; Christensen et al. 2015). Coordination by formal organization has both a vertical and a horizontal version. The vertical version alludes to the principle that the higher the leadership level, the more coordination authority it has. The horizontal one focuses more on actors at the same level working together in different ways (Christensen et al. 2015).

In China, the research of emergency decision-making broadly originated from "SARS" epidemic in 2003. Compared with western countries, both theoretical research and practical experience lag behind the developed countries (Wei Qi et al. 2003). Basically, the coordination structures and mechanisms for emergency decision-making are based on the management systems of the Communist Party of China. All of the emergency decision and arrangements are under the leadership of Central Committee of Communist Party and Party committees at all levels. It is customarily called as "unified leadership".

This emergency decision-making system, in nature, is still a bureaucratic system with a series of traditional coordination mechanisms, which goes back to Weber's theory of bureaucracy. Horizontally, classification management and decision-making is the main mode for crisis management; meanwhile, cross-sectors and integrated agencies play the role of coordination in emergency events. Vertically, territorial management subjects to the administrative guidance of higher authorities; power is more concentrated on the higher authorities. On the tiao-kuai relationships 1, sector segmentation is a common state, the convergence and cooperation of different departments are generally staggered and not smooth. "Table I".

\footnotetext{
Tiao-kuai is the basic structural relationship of central-local or local government systems in China.
} 
TABLE I.

ClASSIFICATIONS FOR DECISION-MAKINGS SYSTEM

\begin{tabular}{|c|l|l|}
\hline \multirow{2}{*}{ horizontal } & \multicolumn{2}{|c|}{ vertical } \\
\cline { 2 - 3 } & \multicolumn{1}{|c|}{ Centralization (higher authority) } & \multicolumn{1}{c|}{ Decentralization (territorial authority) } \\
\hline dispersion & I. classification management \& decision-making & II. classification management \& decision-making \\
\hline comprehensive & III. comprehensive coordination & IV. comprehensive coordination \\
\hline
\end{tabular}

\section{Classification Management ANd DeCision- MAKING}

Classification management refers to the management model based on the types and characteristics of crisis. In China, the competent administrative departments take charge of one or more related emergency events, other relevant departments need to participate in cooperation when emergency occurs. Although the administrative branches have constantly reorganized or reshuffled since the PRC founded, the classification management system was continuing and not suffered serious challenges until the outbreak of SARS in 2003. After the SARS, the government vigorously promoted the administrative legislation and institutional reform for emergency management and decision-making. According to the new regulations, emergent events are entirely divided into four categories, namely, natural disaster, accident calamity, public hygiene incident and social security emergency. "Table II".

TABLE II. TYPES OF EMERGENCIES

\begin{tabular}{|c|l|}
\hline Natural disaster & Floods, droughts, earthquake disaster, geologic hazard, marine disaster, biohazard, hill fire and so on. \\
\hline Accident calamity & $\begin{array}{l}\text { Traffics, accidents involve industrial and commercial enterprises, public facilities and equipments, } \\
\text { environmental pollution and ecological destruction. }\end{array}$ \\
\hline Public hygiene & $\begin{array}{l}\text { Infectious diseases, congregative unknown disease, food safety accident, occupational hazard, animal } \\
\text { epidemics, and others events which may affect public health and life safety }\end{array}$ \\
\hline Social security & Terrorist attacks, economic security incidents, foreign related emergencies \\
\hline
\end{tabular}

According to the principle of classification management, Chinese government has set up a wide range of integrated organizations and coordination agencies in latest years. At the central level, all the departments of the State Council, which bear the responsibilities for crisis management and emergency decision, collaboratively establish a set of coordinate organizations system to deal with major emergencies. These systems involve mechanisms of emergency command, rescue operation and professional rescue teams, forecast warnings, cross-departmental coordination and salvation (Gao Xiaoping 2007). At the local level, people's governments at all level are responsible for overall emergency management and decision-making in their administration area.

\section{COMPREHENSIVE COORDINATION}

Comprehensive coordination includes two meanings: One is related to three types of relationships-government and its subordinate departments, higher administrative organizations and lower level organizations, governmental agencies and civil societies. Another is the coordination of daily works of emergency agencies.

Chinese government has established varieties of coordination organizations to respond to the emergency decision-making of trans-regional, multi-departmental, crossindustrial events. Specifically, these coordination organizations mainly comprise three types: the leading organs, inter-ministerial coordination mechanisms and interregional coordination mechanisms.

Firstly, emergency commissions were set up to ensure the leadership for the emergency decision-making and arrangement at distinct layers. The commissions usually exert effect by establishing emergency management offices, which are always affiliated with the general offices. In April 2006, the General Office of the State Council established an emergency management office, to fulfill the daily management accountabilities of emergency events, information collection and comprehensive coordination. Since then, relevant departments of the State Council and local governments have also set up a number of similar offices. Gradually, the emergency commission and emergency management offices were instituted in succession in the provincial (autonomous regional and municipal).

Secondly, deliberative mechanisms and inter-ministerial joint conference was founded to promote the communication and collaboration. In the longitudinal direction, it forms a hierarchical vertical coordination mode based on authority. Its main carrier is the permanent or temporary deliberative agencies and coordinating organizations (Zhou Zhiren 2013). Since the reform and opening up, Chinese government has set up a variety of cross-departmental and cross-industrial coordinating institutions, which are always task-oriented organizations, in addition to the permanent functional agencies. On the country level, deliberation and coordinating organs contain the Joint Meetings on the handling of the cases of mass disturbances and petition visits, State Flood Prevention and Drought Resistance Headquarters, National Forest Fire Prevention Headquarters, National Headquarters for Earthquake Disaster Mitigation, National Committee for Disaster Reduction, Security Production Committee of the State Council, and Food Safety Commission of the State Council. Since 2013, the State Council streamlined a lot of deliberation institutions and coordination agencies on the one hand, on the other hand, the quantity of the joint meeting led by the host department growing rapidly.

Thirdly, establishing the coordination mechanisms in the adjacent regions has become a new trend of development. With the increase in the complexity, relevance, harmfulness and difficulty of emergent events in recent years, neighbor areas began to promote the cooperation of emergency 
decision-making, to break the geographical closure and capacity gap. The coordination mechanisms for information sharing and emergency response have continuously developed in the Pan Pearl River Delta region, the capital region, the Yangtze River Delta region in latest years.

On the whole, classified management and decisionmaking is still the core mode for the handling of emergency, although Chinese government was constantly strengthening the coordination function of emergency response after SARS event in 2003. But the departmental and classified decisionmaking system performs inefficient in response to the complex emergencies. As administrative departments have their separate operating systems and extent of competence range, the division of responsibilities for different departments is not clear enough. So there was always poor coordination in the process of the emergency response. It is a ubiquitous phenomenon that the overlapping responsibilities, management disjoining and information blocks are common in the decision making. Therefore, the role of the comprehensive coordination mechanism needs to be further clarified and refined.

\section{LOCALIZATION MANAGEMENT AND HIERARCHICAL DECISIONS}

In the vertical direction, the power allocation of emergency management in China is distinctly different from that of western countries. In most developed countries, local governments are fully responsible for local emergency management and decision making, the federal or central government may step in only when it receives a request from a local government. In contrast, China implements the territorial management and hierarchical decision to cope with the crisis.

Territorial management refers to the local government above county-level should be responsible for handling the emergency incident within their respective jurisdiction. When an emergency occurs, the related authorities would start up the emergency response mechanism immediately according to their respective administrative areas.

Hierarchical decision mainly means that determining the different levels of government to deal with emergencies according to the scope and levels of the impact on emergencies. In the light of the possible hazards, the degree and situation of urgencies, emergencies can be classified into particularly severe (I), severe (II), somewhat severe (III), common (IV). According to Emergency Response Law and Overall Emergency Preplan for National Sudden Public Incidents, the government at prefecture-level and countylevel should led the decision-making in the field IV and III, mainly involve the natural disaster, accident calamity, public hygiene incident. Provincial government led emergency decision-making in the field I and II. The State Council shall be responsible for handling unexpected events beyond the capacity of a provincial government or beyond a provincial administrative region. In particular, social security incidents are usually disposed of by the county government at the county-level, but the superior government can deal directly with it when necessary.
In addition, the centralization of decision making is also very necessary. Due to the lack of sufficient authority and effective incentive, local governments frequently couldn't facilitate adequate response and coordination in the process of emergency response. Unified leadership and centralized decision- making are often applied to treating with major emergencies.

In contemporary China, the central or the superior government makes decisions, but they usually will not be responsible for making mistakes. Instead, the local and lower level government will be penalized for the poor implementation of supervisors' decisions. Under the high intensity of accountability mechanisms, the behavior of negatively waiting instructions in supervisor or disguising accidents has become the rational choice of the local government or lower department. The phenomenon of falsely report, failing to report, deliberately hiding from report is very common.

In fact, the territorial management tends to evolve into vertical management led by higher authorities. Hierarchical decision making is also difficult to avoid the limitations of centralized decision making. As Tom Burns said, the lower level a person is, more explicit his task would be limited. Accordingly, he has less information and ability to make a decision.

\section{TIAO-KUAI RELATIONSHIP}

Tiao-Kuai(also known as tiáotiáo-kuàikuài) is the basic structural relationship of administrative organization system in China, which affects and restricts the whole government's administrative management at different levels and in various fields. The term tiáo refers to the vertical lines of authority on various sectors reaching down from the ministries of the central government. Kuài refers to the horizontal level of authority of the territorial government at the provincial or local level.

Tiao-Kuai relationships comprise three major forms: The first one is the relationship between the superior functional departments (tiáotiáo) and subordinate government (kuàikuài). The second one is the relationship between the superior functional departments and subordinate functional departments. The third one is the relationship superior government and subordinate government.

In the practice of emergency management, tiao-kuai relationships not only include the relationship of vertical management departments and local government, but also the relationship between the central and local state owned enterprises and the local governments.

So far, the division of accountabilities between the tiáo and kuài is not clearly defined institutional in the emergency management. There has not formed a standardized and orderly collaborative mechanism. Meanwhile, it usually lacks of convergence, communication, cooperation as well as the smoothness of management. Specifically, there are two categories of problems. The first case, kuàikuài is overwhelmed by tiáotiáo. It means that the problems occurred in the kuàikuài, but the decision-making power is 
configured on the tiáotiáo. The accredited units in an area are subject to the guidance of the superior competent departments. Local government relies too much on the emergency management of the accredited units. Another case is that tiáotiáo is overwhelmed by kuàikuài, the decision-making power is configured on the latter. Upper competent department handles the vocational affair, correspondingly, the local government is responsible for the distribution of personnel, finance and goods. It also led to a problem that the competent department is highly dependent on local government. Local government is not easy to adopt the views of the vertical management department in the decision-making process.

\section{PROCESS OF DECISION-MAKING}

The decision-making process reflects the dynamic relationship of decision-making power. It focuses on the decision-making body how to make decision on the emergencies. National decision-making system is divided into external brain and internal brain. The external brain includes the domestic think tanks, masses and provincial institutions (Party committee, administrative organ, legislature, Political Consultative Conference), internal brain is made up of central authorities, which takes the Central Committee of the Communist Party of China as the core, including the State Council, the National People's Congress, the CPPCC National Committee. In the past 60 years, the decision-making of the central government level has been transformed from the individual model and collective model to the consensus model that based on collective decision making. Consensus model is generally considered to have a higher degree of democratization and scientific. This is a consensus type of collective decision making, which is beneficial to solve the information asymmetry in the decision-making process. Consensus decision making is very useful for routine decision making, but it is not conducive to the sudden major emergencies. On the one hand, the central government policy is influenced by the system of separation of powers and departmentalism, the highest level of decision-making can't fully control the decision-making process. On the contrary, the decisionmaking power is shared by the decision-making department and the platform which is divided vertically and horizontally. The decision-making process is often full of competition and conflict between different organizations. On the other hand, in view of the major emergencies, the high-level decisionmaking subject often faced with multiple aspects of the pressure, it may cost too much time, eventually unable to make timely and effective decision-making.

According to "the kernel layer- edge layer"(KLEL) analysis framework, China's emergency response to emergencies can be summarized as "fragmentation decision model", which consists of two characteristics: boundary layer decentralized decision-making and the kernel control. It means that the boundary layer is fragmented, decentralized state, yet the core of China's emergency decision-making is a rigid bureaucratic functional organization, which is always with the basic feature of vertical "power - responsibility". Decision making power is presented as top-down, only the highest top level is likely to look at the overall situation.

The emergency decision-making mode, which presents super stability, fragmentation, hierarchy model, has a strong organizational mobilization capacity in the normal situation. However, it couldn't timely resolve the emergency with complex and volatile situation. It is also unable to promote cross-border cooperation for related subject. In addition, it may lead to the lag of emergency decision making and disposal. In the end, the emergency decision becomes a passive mode of "impact-response".

\section{PERCEIVED COORDINATION QUALITY}

We now discuss the issue with coordination quality by using different coordination mechanisms. "Table III" reveals the administrative staff's view on state affairs within policy scope. This table presents that respondents believe coordination is not good, except the vertical direction in their own policy areas. Horizontal coordination of the policy areas with international and ultra state agencies is regarded as very poor. Local coordination, regional organizations and stakeholders' attitudes are somewhere fell in between. Onethird of respondents believe that in the past five years, some changes have occurred. Another one-third view that the situation is going worsening, and percent of 33 did not report any changes. It can be concluded that the emergency decision system reform is very important, but the progress is slow or observers can't see the change.

TABLE III. COORDINATION QUALITY*. N (AVERAGE): 200

\begin{tabular}{|c|c|c|c|}
\hline & improved & Neither & Poor \\
\hline Vertical coordination/within own policy area & 51 & 28 & 21 \\
\hline Horizontal coordination/across policy areas & 38 & 26 & 36 \\
\hline With regional/local governments & 41 & 30 & 30 \\
\hline With international/supranational bodies & 26 & 35 & 38 \\
\hline With private sector/civil society actors & 37 & 38 & 25 \\
\hline
\end{tabular}

\section{CONCLUSION}

The paper combines views from formal structural arrangements for emergency decision-making in China, with data on the practical coordination mechanisms. The structural variations on centralization or decentralization and the use of hierarchical mechanisms, lead agencies and coordination arrangements are large. It is complex, loose and ambiguous to coordinate the quality perception.

A major conclusion is that there is no an optimal solution or coordinate formula can overcome the uncertainty and ambiguity of the government structure, and making policy 
choices each people will accept. In the contemporary government system, the emergency decision is dependent and varied, which has a strong and multi dimensional pressure on the coordination system. Finding a workable 'smart practice' or a balance between hierarchical instruments and network solutions is complicated and context-dependent. Finding a feasible balance between "intelligent practice" or layered instrumentation and network solutions is very complex. This is not a necessary issue, but it also provides a flexible adjustment to respond to different sizes and types of emergency situations.

\section{REFERENCES}

[1] Agranoff, R.2006. Inside collaborative networks: Ten lessons for public managers. Public Administration Review, 66(1), 56-65.

[2] Tom Christensen, Per Lægreid and Lise Rykkja. 2015. 'The Challenges of Coordination in National Security Management - the Case of the Terrorist Attack in Norway', International Review of Administrative Sciences, 82, 2, 352-72.

[3] Rosenthal, U., M.T. Charles and P. 't Hart (eds). 1989. Coping with Crises: The Management of Disasters, Riots and Terrorism. Springfield, IL: Charles C. Thomas.

[4] Rosenthal, U., \& Kouzmin, A. (1997). Crises and crisis management:Toward comprehensive government decision making. Journal of Public Administration Research \& Theory, 7(2), 276-3705.

[5] Xuelan, Zhong Kaibin(2014), Emergency decision making: theoretical framework and studies,46-50. 